\title{
Application of MODIS-derived active fire radiative energy to fire disaster and smoke pollution monitoring
}

\author{
Charles Ichoku', Yoram J. Kaufman ${ }^{2}$, Wei Min $\mathrm{Hao}^{3}$ and Shahid Habib \\ 1 Science Systems and Applications Inc., NASA/GSFC code 913, Greenbelt, MD 20771. \\ 2 Laboratory for Atmospheres, NASA/GSFC code 913, Greenbelt, MD 20771. \\ ${ }_{3}^{3}$ Fire Sciences Laboratory, USDA Forest Service, P. O. Box 8089, Missoula, MT 59807. \\ ${ }^{4}$ Directorate of Earth Sciences, NASA/GSFC code 900, Greenbelt, MD 20771.
}

\begin{abstract}
The radiative energy emitted by large fires and the corresponding smoke aerosol loading are simultaneously measured from the MODIS sensor from both the Terra and Aqua satellites. Quantitative relationships between the rates of emission of fire radiative energy and smoke are being developed for different fire-prone regions of the globe. Preliminary results are presented. When fully developed, the system will enable the use of MODIS direct broadcast fire data for near real-time monitoring of fire strength and smoke emission as well as forecasting of fire progression and smoke dispersion, several hours to a few days in advance.
\end{abstract}

\section{INTRODUCTION}

Fires are formidable agents of disaster, voraciously consuming natural and man-made resources and concurrently emitting particulate and gaseous pollutants into the atmosphere. Remote sensing provides a powerful means of fire monitoring and disaster mitigation. Each of the two Earth Observing System (EOS) Satellites, Terra and Aqua, is carrying the Moderate Resolution Imaging Spectroradiometer (MODIS) sensor aboard. MODIS has 36 spectral channels spread across the 0.4 to $14.4 \mu \mathrm{m}$ wavelength range approximately, with at-nadir spatial resolutions of $0.25 \mathrm{~km}(2$ channels), $0.50 \mathrm{~km}$ (5 channels), and $1 \mathrm{~km}$ ( 29 channels). Each MODIS covers nearly the entire globe once in the daytime and once in the nighttime daily, making a (Terra + Aqua) total of four measurements every 24 hours.

Earlier fire remote sensing activities were limited to identifying fire locations, because the sensors used were easily saturated by strong signal from large or intense fires. With the enhanced radiometric range of the MODIS 4- $\mu \mathrm{m}$ fire channel, it is now possible to measure from space the rate of emission of radiative energy from fires [1]. In addition, MODIS operationally provides the total column loading and size parameters of smoke emitted by fires [2], among other aerosols. The availability of high quality fire and aerosol parameters from the same sensor, in an operational mode, offers a great opportunity for simultaneous monitoring of the severity of fire disasters and associated smoke pollution.

Therefore, the focus of this application is to take advantage of this new data resource in developing tools for fire disaster management and air quality monitoring. From various field and airborne experiments, the rate of emission of fire radiative energy has been shown to be related to the rate of biomass consumption [3] as well as to the rate of smoke emission [1]. The objective of this research is to establish this relationship between the rates of emission of radiative energy and smoke from satellite observations for fires in different biomes and regions. The derived biomass emission coefficients, together with fire radiative energy from the MODIS data acquired by the Forest Service Direct Broadcast system, will be assimilated into fire progression and Weather Research and Forecasting (WRF)-Smoke Dispersion models. This project will provide near real-time fire intensity and smoke emissions, as well as forecasts of fire spread rate and smoke dispersion, for use in decision support systems for wide-ranging applications, including for firefighting, alerts, early warning systems, evacuation, emissions inventory, weather, and climate.

\section{MODIS ACTIVE FIRE DATA}

The operational fire detection with MODIS is accomplished at 1-km spatial resolution, using mainly the 4$\mu \mathrm{m}$ and $11-\mu \mathrm{m}$ channels [1,4]. However, the 0.66- $\mu \mathrm{m}$ and $0.87-\mu \mathrm{m}$ channels are used for filtering out pixels contaminated by sun glint. On detecting the $1-\mathrm{km}$ resolution pixels containing fire, the MODIS fire algorithm uses the 4$\mu \mathrm{m}$ brightness temperature of the fire pixel and the background to compute the rate at which the fire radiative energy (FRE) is emitted. This rate of emission of FRE per second $(\mathrm{MJ} / \mathrm{s})$, which is referred to as the Fire Radiative Power (FRP) in the MODIS fire product, is expressed in MW per pixel. The full description of the current MODIS fire algorithm, products, and validation activity is given in [4], while the detailed formulation for deriving FRP is given in [1].

\section{Modis AEROSOL DATA}

Atmospheric aerosols include smoke, dust, sea salt, urban/industrial pollution, and other species. Aerosol parameters are retrieved from MODIS data at $10-\mathrm{km}$ spatial resolution (level 2) only during the daytime, both over land and ocean [2]. Over land, the MODIS-retrieved aerosol parameters include: total column aerosol optical thickness (AOT or $\tau_{\mathrm{a} \lambda}$ ) at $0.47,0.55$ and $0.66 \mu \mathrm{m}$ wavelengths, Angstrom exponent $(\alpha)$, and the fraction of AOT contributed 
by the fine size mode aerosols (under the assumption that aerosols are composed of two main size modes: coarse and fine). AOT expresses the total column aerosol loading in each pixel, and is the most significant parameter used for various kinds of studies involving atmospheric aerosols. Although the fine mode fraction gives a general idea of aerosol type, MODIS does not specifically distinguish one aerosol type from another. Therefore, this study combining fire and aerosol data will enable accurate quantification of smoke aerosol, as distinct from other species.

\section{MODIS FIRE/AEROSOL DATA ANALYSIS}

The basis of the application proposed in this paper is the relationship between the rates of emission of fire radiative energy and the corresponding smoke aerosol. To establish this relationship in a rudimentary way, various large regions of the world where fires occur seasonally were identified. Fig. 1 shows six regions on which the study was conducted, namely Southern Africa, Siberia, Western US, the Amazon, Northern Australia, and Western Russia. For each of the six regions, MODIS-measured FRP and AOT parameters were extracted for the year 2002 both from Terra- and AquaMODIS.

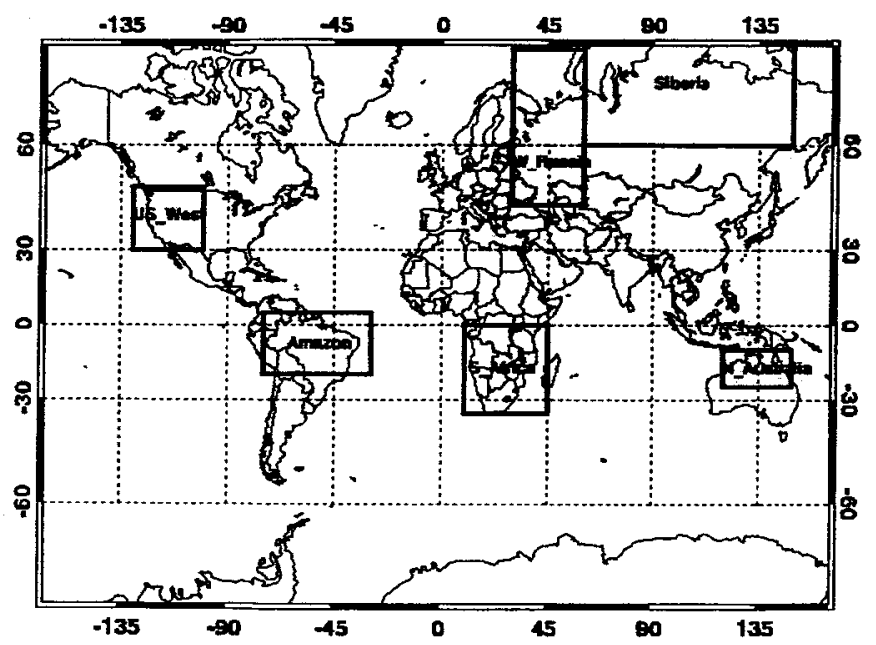

Fig. 1. Global map showing six selected regions used for the preliminary study of the relationships and cycles of rate of emission of fire radiative energy, $E_{f}$ and aerosol optical thickness, $A O T$, both derived from MODIS.

Based on the assumption that the average lifetime of smoke in the atmosphere is about one week, weekly regional statistics of the FRP and AOT were computed for each of the regions for further analysis. For FRP, the weekly total was calculated for each region, since it is the total energy for the region (as opposed to average energy per pixel) that determines the emitted smoke amount. However, to make the values comparable between regions, the total regional FRP is divided by the area of the region in $\mathrm{deg}^{2}$. On the other hand, since the smoke density would be expressed by the average AOT over each region, the weekly mean AOT was simply derived for each region. The total weekly FRP/deg ${ }^{2}$ (designated by $E_{f}$ ) was plotted against the mean weekly AOT for each region (Fig. 2a,b). There is an appreciably linear relationship between $E_{f}$ and the weekly mean AOT. Note that in Fig. 2b the abscissa (the $E_{f}$ axis) has a logarithmic scale. Therefore, for the three regions represented on Fig. 2b (Amazon, Australia, WRussia) AOT appears to be linearly related (not directly to $E_{f}$ ) but to $\log E_{f}$. The relationships as well as other statistical information are listed in Table 1. It is important to emphasize that these results are only preliminary. Nevertheless these relationships have provided the encouragement to undertake more in-depth investigation in this area of research.
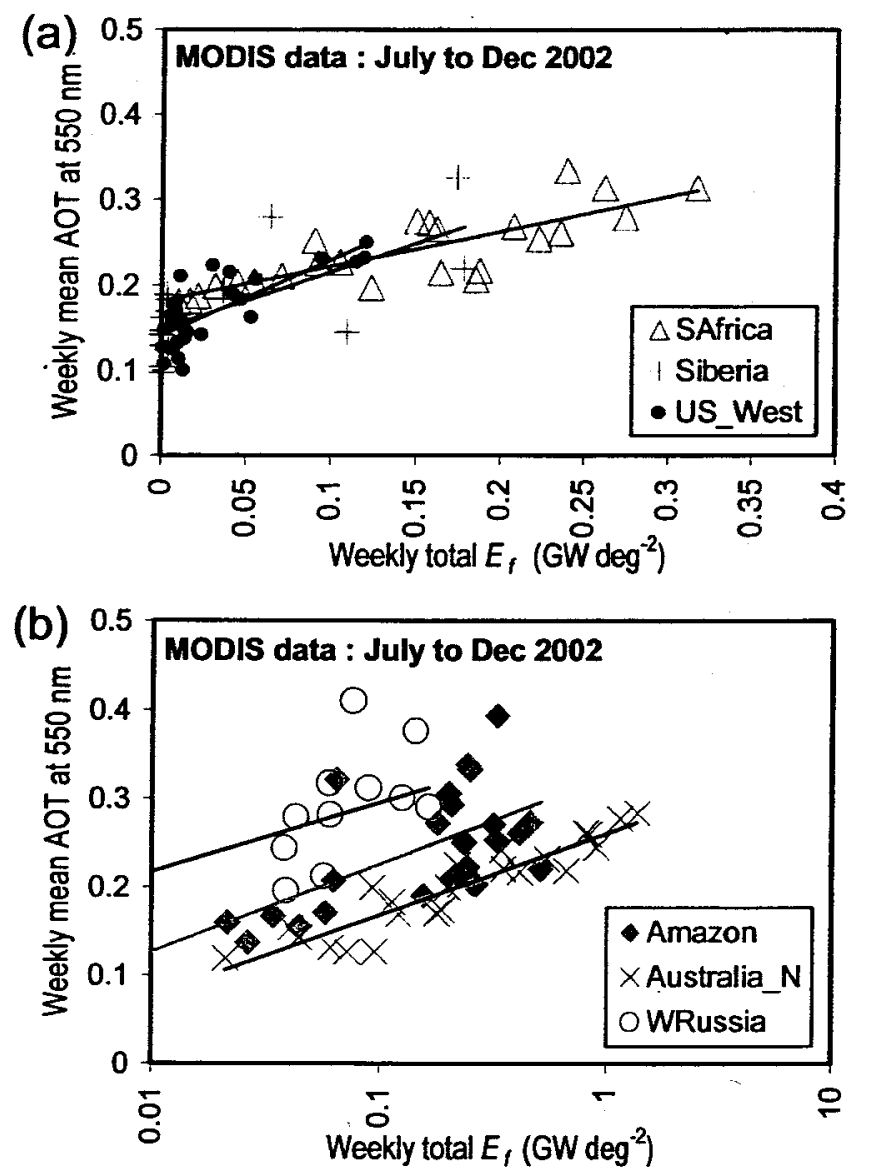

Fig. 5. MODIS regional weekly mean aerosol optical thickness $(A O T)$ at $550 \mathrm{~nm}$ against weekly total fire radiative power $\left(E_{f}\right)$ per degree squared (in GW). Best linear fits are shown for the group of points representing each region. Note that the horizontal axis on the left panel is plotted with a log scale. The correlation coefficients are listed in Table 1.

\section{RESEARCH DIRECTION AND APPLICATIONS}

Currently, research is in progress to develop clear and accurate relationships between the rates of emission of fire radiative energy and smoke aerosol. Traditional methods for deriving emission rates employ the use of emission factors $e_{x}$ (in $\mathrm{g}$ of emitted species $x$ per $\mathrm{kg}$ of biomass burned), which is then used to estimate emission based on the mass of combusted biomass. However, the mass of burned biomass is 
difficult to measure from satellites. Current remote sensing methods attempt to estimate burned biomass mass either from the burned area (which is available only after the fire is over) or from fire pixel counts (which do not have a physical meaning, and can be confusing when the pixel spatial resolution changes). As a result, it has hitherto been difficult to monitor fire progression and smoke emission effectively in near real time.

In this research, a new technique, using the fire radiative power (FRP) and aerosol optical thickness (both of which are measured by MODIS onboard the EOS Terra and Aqua satellites) to calculate FRE-based emission rates, is being developed. Therefore, instead of the traditional emission factors $e_{x}$, a new parameter called "fire radiative energy emission coefficient", $C_{e}$ (in $\mathrm{g}$ of emitted matter per Mjoule of radiative energy), which is related to the rate of biomass consumption, will be defined and derived for different regions and biomes. $C_{e}$ will be used in estimating smoke emissions from remotely-sensed FRP, which has the same physical meaning regardless of sensor or scale of observation.

There is tremendous application potential for the availability of $C_{e}$ in combination with FRP, especially when received through the MODIS direct broadcast system in real time. FRP can be used to monitor the strength of fire in nearreal time and can be multiplied by $C_{e}$ to derive the rate of generation of smoke, also in near-real time. Furthermore, this parameter $\left(C_{e}\right)$ and measurement (FRP) can be applied in forecast models to predict the progression of fire and smoke dispersion for several hours or days in advance. Such information will be beneficial for planning fire fighting and evacuation operations as well as for smoke pollution advance warning, in order to take measures to limit health risks. The results will also be very useful for keeping accurate inventory of fires and generated smoke, and for quantifying their effects on the environment, weather, and climate.

\section{REFERENCES}

[1] Y. J. Kaufman, C. O. Justice, L. P. Flynn, J. D. Kendall, E. M. Prins, L. Giglio, D. E. Ward, W. P. Menzel, and A. W. Setzer, 1998, Potential global fire monitoring from EOS-MODIS. Joumal of Geophysical Research, 103, 32215-32238.

[2] C. Ichoku, D. A. Chu, S. Mattoo, Y. J. Kaufman, L. A. Remer, D. Tanré, I. Slutsker, and B. Holben, A spatio-temporal approach for global validation and analysis of MODIS aerosol products. Geophys. Res. Lett., 29, 10.1029/2001GL013206, 2002.

[3] M. J., Wooster, Small-scale experimental testing of fire radiative energy for quantifying mass combusted in natural vegetation fires, Geophys. Res. Lett., 29(21), 2027, doi:10.1029/2002GL015487, 2002.

[4] C.O. Justice, L. Giglio, S. Korontzi, J. Owens, J. T. Morisette, D. Roy, J. Descloitres, S. Alleaume, F. Petitcolin, and Y. Kaufman, The MODIS fire products, Remote Sensing of Environment vol. 83, no.1-2 : 244-62, Nov. 2002.

\begin{tabular}{|c|c|c|c|c|c|c|}
\hline Regions & $\boldsymbol{N}_{f}$ & Edpixel (MW) & Total $E_{f} / \mathrm{deg}^{2}$ & $\operatorname{AOT}\left(\tau_{a}\right)$ & Best fit equation & $r$ \\
\hline S.Africa & 140413 & 30 & 27343 & 0.26 & $\tau_{a}=0187+0.408 F_{w}$ & 0.83 \\
\hline W.Russia & 24858 & 34 & 2473 & 0.31 & $\tau_{\mathrm{a}}=0.37+0.078 \log \left(F_{w}\right)$ & 0.82 \\
\hline Amazon & 137994 & 40 & 39527 & 0.26 & $\tau_{a}=0.32+0.10 \log \left(F_{w}\right)$ & 0.67 \\
\hline N.Australia & 86868 & 48 & 58807 & 0.23 & $\tau_{a}=0.26+0.092 \log \left(F_{w}\right)$ & 0.93 \\
\hline Siberia & 25938 & 51 & 3484 & 0.25 & $\tau_{\mathrm{a}}=0148+0.678 F_{\mathrm{w}}$ & 0.69 \\
\hline US_West & 7720 & 67 & 529 & 0.20 & $\tau_{\mathrm{a}}=0141+0.888 F_{\mathrm{w}}$ & 0.78 \\
\hline
\end{tabular}

$N_{\mathrm{f}}=$ Number of fire pixels; $E_{\mathrm{f}}$ rate of emission of fire radiative energy; $F_{\mathrm{w}}=$ weekly total $E_{\mathrm{f}}$ per degree squared 